\title{
Hsp90 Inhibitor AB-010
}

National Cancer Institute

\section{Source}

National Cancer Institute. Hsp90 Inhibitor AB-010. NCI Thesaurus. Code C82691.

An orally bioavailable nanoparticle albumin-bound inhibitor of heat shock protein 90 (Hsp90) with potential antineoplastic activity. Hsp90 inhibitor AB-010 selectively binds to Hsp90, inhibiting its chaperone function and promoting the degradation of oncogenic signaling proteins involved in tumor cell proliferation and survival. This agent may inhibit the growth of a wide variety of cancer cell types; the incorporation of albumin into its formulation may facilitate its endothelial transcytosis through the gp60-regulated albumin transport pathway. Hsp90, a chaperone protein upregulated in a variety of tumor cells, regulates the folding and degradation of many oncogenic signaling proteins. 